\title{
Comparative Evaluation of the Mechanical Properties of Zinc-reinforced Glass Ionomer Cement and Glass Ionomer Type IX Cement: An In Vitro Study
}

\author{
Krishna Patil ${ }^{1}$, Alok Patel ${ }^{2}$, Sanket Kunte ${ }^{3}$, Preetam Shah ${ }^{4}$, Buneet Kaur ${ }^{5}$, Sujatha Paranna ${ }^{6}$
}

\begin{abstract}
Aims and objectives: The aims and objectives of this study were to evaluate and compare the flexural strength and microhardness of zinc reinforced glass ionomer cement and glass ionomer type IX cement.

Materials and methods: The sample size of twenty each of group I (zinc-reinforced glass ionomer cement) and group II (glass ionomer type IX cement) were selected. The samples were prepared in the customized steel molds and subjected to test for flexural strength and microhardness. The flexural strength was determined by the three-point bending test. After determining the flexural strength, the fragments were used to determine Vickers Hardness by means of an automatic microhardness indenter. The flexural strength and microhardness was calculated for all samples and subjected to statistical analysis. Two sample $t$-test with unequal variances were used, as the data are found to be from the same material. The normality was checked by using the usual normal probability plot. For flexural strength, $p$ value was found to be 0.007530 . Hence, zinc-reinforced glass ionomer cement was superior to glass ionomer type IX cement. For microhardness the $p$ value was found to be 0.0023 . So, glass ionomer type IX cement was superior to zinc reinforced glass ionomer cement.

Conclusion: The zinc-reinforced glass ionomer cement showed enhanced flexural strength when compared to glass ionomer type IX cement, thus increasing the longevity whereas glass ionomer type IX cement had a better microhardness than zinc-reinforced glass ionomer cement. Hence, the mechanical properties of various materials should be considered for the long-term clinical success by selecting the appropriate material based on the clinical condition.
\end{abstract}

Keywords: Aluminosilicate, Glass ionomer cements, Zinc reinforcement.

International Journal of Clinical Pediatric Dentistry (2020): 10.5005/jp-journals-10005-1798

\section{INTRODUCTION}

In dentistry, especially pedodontics, glass ionomer cements (GICs) are considered to be the material of choice on tooth surfaces which do not bear high stress. In 1971, GICs were first introduced in Europe, and in 1977, it was marketed in the United States. ${ }^{1}$ "Glass" powder and "ionomer" acid are major components of this cement. Glass ionomer cement can be defined as a water-based material that hardens following an acid-base reaction between the basic fluoroaluminosilicate glass powder and an acidic solution of polyacrylic acid.

Glass ionomer cements have many clinical applications. The property that differentiates GIC from various restorative materials is its chemistry, which is self-adhesive to the tooth structure and has caries-protective release of fluoride at the margins of restorations, along with its ability to recharge by exposure to fluoride-containing agents. The other unique property is its moisture tolerance which increases its clinical application.

Since then, to improve the mechanical properties, the cement has being modified resulting in various commercially available GIC materials. The properties of conventional GIC such as biocompatibility, low cytotoxicity, ${ }^{2}$ fluoride release, and limited microleakage ${ }^{3}$ have led to its use by various dentists. Poor polishability, susceptibility to dehydration, and moisture contamination during initial setting, low fracture toughness, and flexural strength (FS) ${ }^{4}$ are the undesirable properties of GIC. Several advantages, such as adhesion to the moist enamel and dentin without the use of any intermediate agent and its anticariogenic properties, are better than permanent filling
1,6 Department of Pedodontics and Preventive Dentistry, Bharati Vidyapeeth (Deemed to be University), Dental College and Hospital, Sangli, Maharashtra, India

${ }^{2-4}$ Department of Pediatrics and Preventive Dentistry, Bharati Vidyapeeth (Deemed to be University), Dental College and Hospital, Pune, Maharashtra, India

${ }^{5}$ Department of Pedodontics and Preventive Dentistry, Sri Guru Ram Das Institute of Dental Sciences and Research, Amritsar, Punjab, India

Corresponding Author: Krishna Patil, Department of Pedodontics and Preventive Dentistry, Bharati Vidyapeeth (Deemed to be University), Dental College and Hospital, Sangli, Maharashtra, India, Phone: +91 9420419100, e-mail: krishnapatil1000@gmail.com

How to cite this article: Patil K, Patel A, Kunte S, et al. Comparative Evaluation of the Mechanical Properties of Zinc-reinforced Glass Ionomer Cement and Glass lonomer Type IX Cement: An In Vitro Study. Int J Clin Pediatr Dent 2020;13(4):381-389.

Source of support: Nil

Conflict of interest: None

materials like resin-based composites. In everyday dental practice, biocompatibility and low coefficient of thermal expansion support their valuable position. ${ }^{5}$

In the first 10 minutes of the hardening process, there is a slow release of calcium ions within the matrix, followed by aluminum ions. ${ }^{6}$ At this time, the material is very frail to dehydration. Hence, in clinical situation, the gain or loss of liquid can adversely affect the final properties of the restoration. ${ }^{7}$ 
Sealing the cavity, prevention of tooth destruction, rendering the tooth and the tooth-restoration interface caries resistant, and ease of use in a clinical scenario must be included. Along with it, the material selected for the procedure must be intended to be effective to sustain the grueling environment of the mouth for the particular time period. While considering restorative objectives for children, one must also consider the general guidelines defined for the same objectives.

In dentistry, several restorative materials have been introduced claiming to have nearly ideal properties to be used in clinical conditions. Although there are various restorative materials available with numerous attributes, it lacks some of the desirable properties.

To enhance the material stability, manufacturers recently introduced a newer type of GIC (ChemFil ${ }^{\mathrm{TM}}$ Rock, Dentsply), claiming that product performance is irrelevant to the surface protection by resin coating. The high strength of the new GIC with similar working time and application as regular GIC is due to the enhanced setting reaction by the presence of zinc in glass particles. The presence of zinc in $\mathrm{GIC}$ has many advantages, making it more durable and also can be used in stress-bearing situations along with restoration of posterior teeth. However, only few studies have been evaluated to know the desirable properties of the new GIC.

Hence, the present in vitro research was planned to evaluate the performance of zinc-containing GIC over conventional GIC.

\section{Aims and Objectives}

\section{Aims}

The aims of this research were to study and compare the mechanical properties of two different cements: zinc-reinforced GIC and glass ionomer type IX cement.

\section{Objectives}

- To evaluate the FS of zinc-reinforced GIC (Chemfil ${ }^{\mathrm{TM}}$ Rock Capsule, Dentsply).

- To evaluate the FS of GIC type IX (GC America).

- To evaluate the microhardness of zinc-reinforced GIC (Chemfil ${ }^{\mathrm{TM}}$ Rock Capsule, Dentsply).

- To evaluate the microhardness of GIC type IX (GC America).

- To compare the FS and microhardness of zinc-reinforced GIC with GIC type IX.

\section{Materials and Methods}

\section{Armamentarium}

- Customized steel mold of size $40 \mathrm{~mm} \times 5 \mathrm{~mm} \times 2 \mathrm{~mm}$ (length $\times$ breadth $\times$ height)

- Universal testing machine (three-point bending test)

- Microhardness tester

- Glass slab

- Restorative instruments

- Mixing pad

- Agate (plastic spatula)

- Sandpaper

- Amalgamator (Fig. 1)

- Extruder (Dentsply Company)

\section{Materials}

Group I: Zinc-reinforced GIC (ChemFil ${ }^{\mathrm{TM}}$ Rock Capsule Dentsply Company, Caulk) (Fig. 2).

Group II: GIC type IX (GC America Inc.) (Fig. 3).

\section{Methods}

Twenty samples each of group I (zinc-reinforced GIC) and group II (GIC type IX) were prepared in the customized steel molds of size $40 \mathrm{~mm} \times 5 \mathrm{~mm} \times 2 \mathrm{~mm}$ (length $\times$ breadth $\times$ height) (Fig. 4). One surface of each sample was made glossy with the help of a glass slab as a lid.

Both the cements were mixed according to the manufacturer's directions for use, at room temperature $\left(21^{\circ} \mathrm{C}\right)$ allowing them to set for 20 minutes at room temperature in the mold.

\section{Manipulation of Material}

\section{Group I: Zinc-reinforced Glass lononmer Cement}

It was dispensed in a capsule. The capsule was taken and was placed in an amalgamator. The lid of the capsule was pressed so that the liquid and powder present in the capsule mix with each other. The material was oscillated at a speed of 4000-4500 rpm for 16 seconds. Then, it was taken in an extruder and dispensed into a customized stainless steel mold of size $40 \mathrm{~mm} \times 5 \mathrm{~mm} \times 2 \mathrm{~mm}$. After the cement was set, it is retrieved from the mold.

\section{Group II: Glass lononmer Cement Type IX}

A mixing pad and agate spatula was taken with GIC powder and liquid in the ratio of 5:5. The cement was manipulated by the folding method. The cement is transported to the customized steel mold with the help of a cement carrier. After the cement was set (setting time), it was retrieved from it.

\section{Preparation of Samples}

After the cements had been set, they were retrieved from the mold and any flush material was trimmed away with the sandpaper. All the samples were then stored in $37^{\circ} \mathrm{C}$ prior to testing for 24 hours.

\section{Macromechanical Characteristics \\ Measurement of FS}

The FS was determined by the three-point bending test in analogy to ISO/DIN 4049:1998. The samples were loaded in a three-point bending test device, which is constructed according to the guidelines of ASTM D790 with $30-\mathrm{mm}$ distance between the supports. The cross-head speed was set at $3.0 \mathrm{~mm} /$ minute. The universal testing machine measured the force during bending as

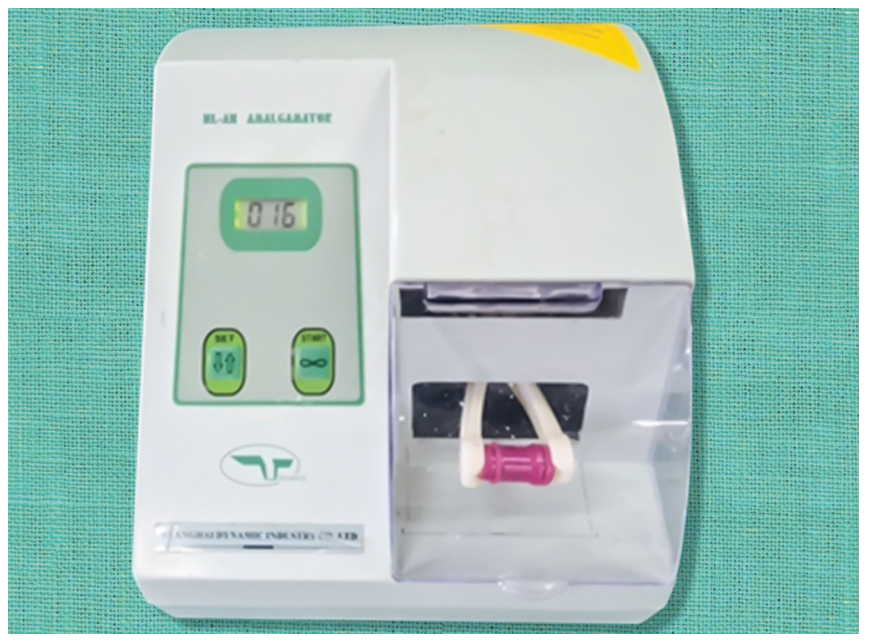

Fig. 1: Amalgamator 


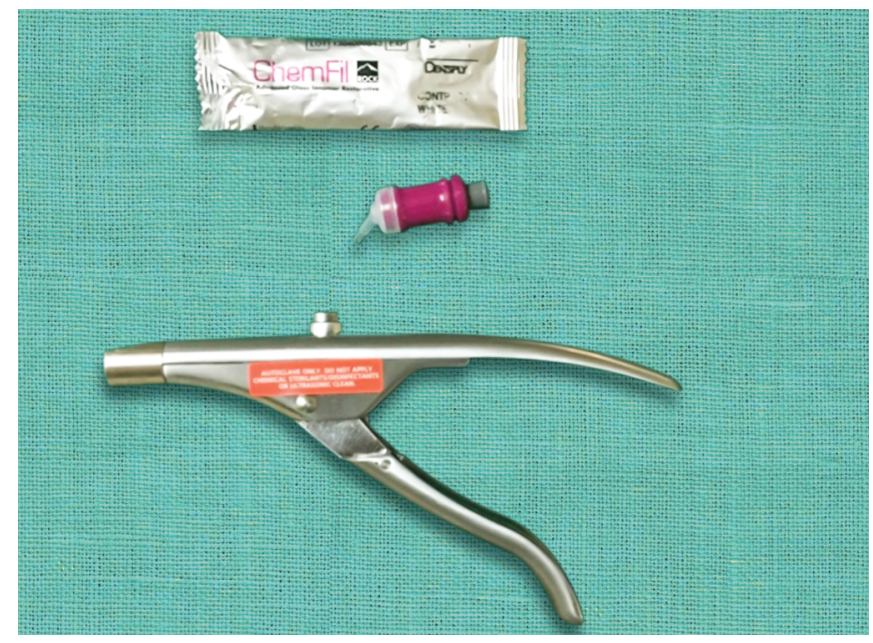

Fig. 2: Zinc-reinforced glass ionomer cement with extruder

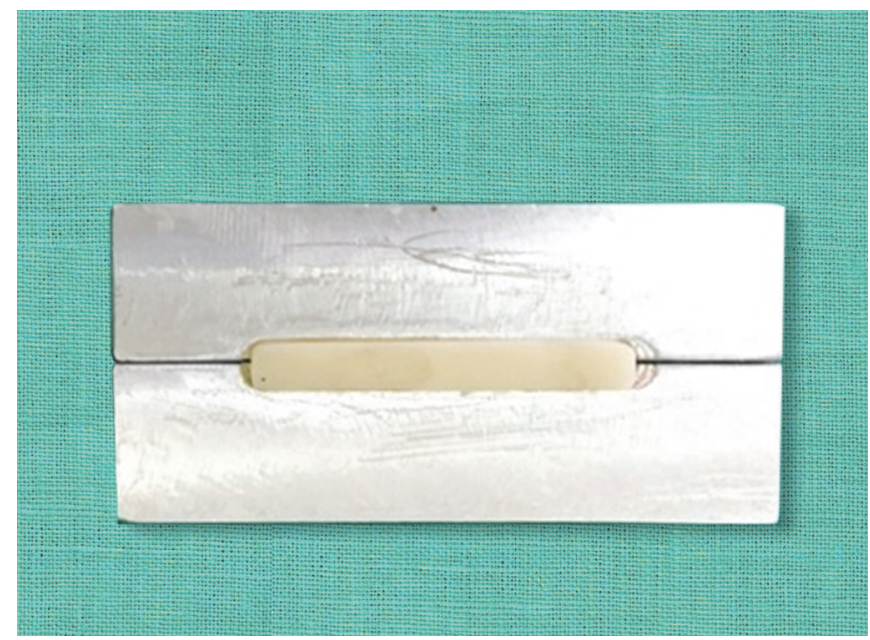

Fig. 4: Steel mold of size $40 \mathrm{~mm} \times 5 \mathrm{~mm} \times 2 \mathrm{~mm}$

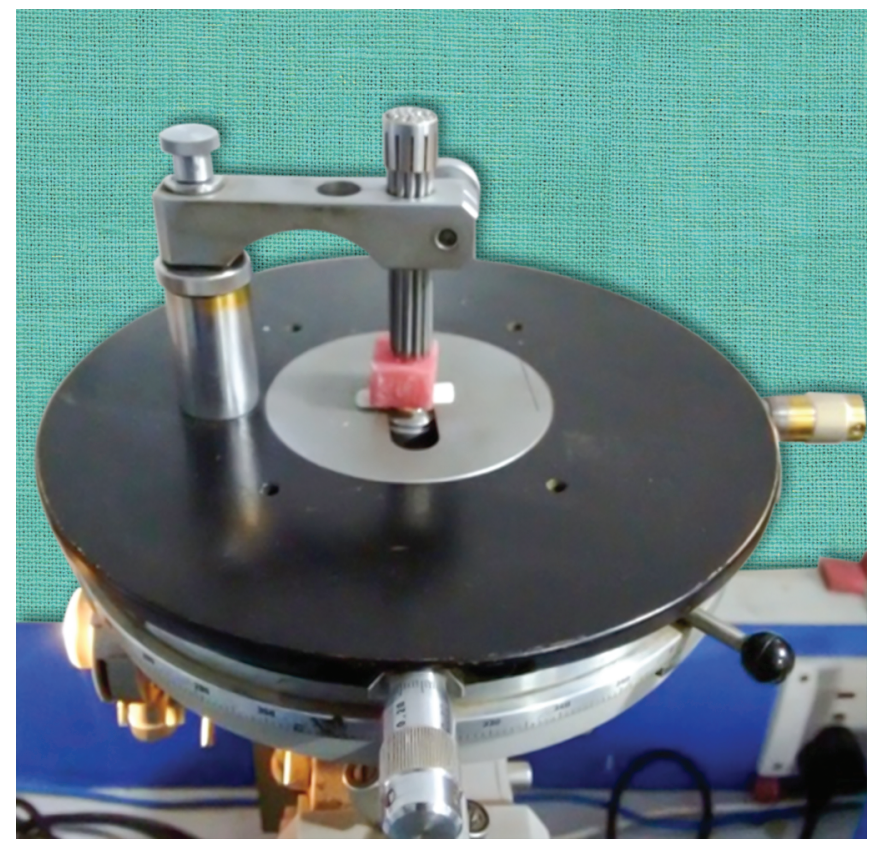

Fig. 6: Load applied on the samples for Vickers hardness test

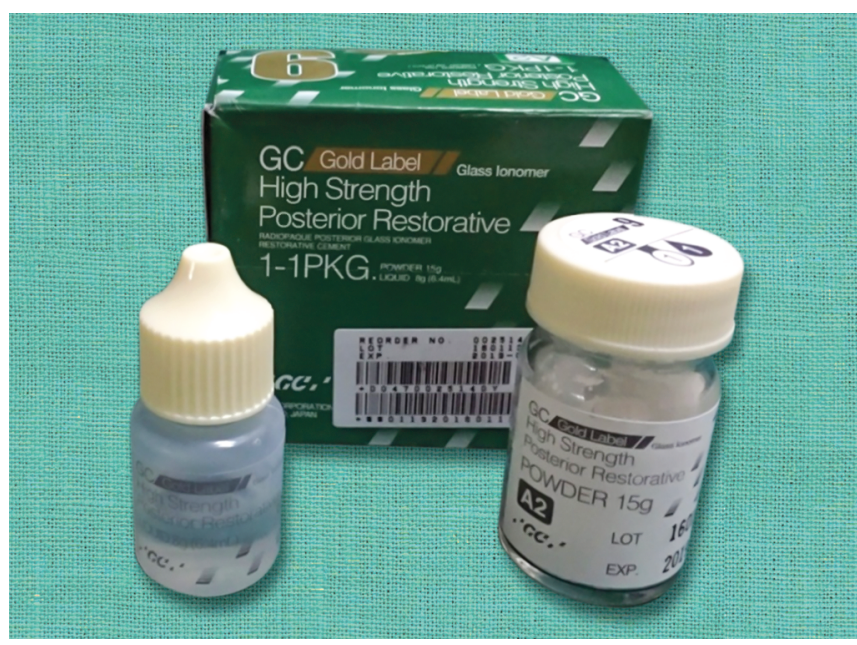

Fig. 3: Glass ionomer cement type IX

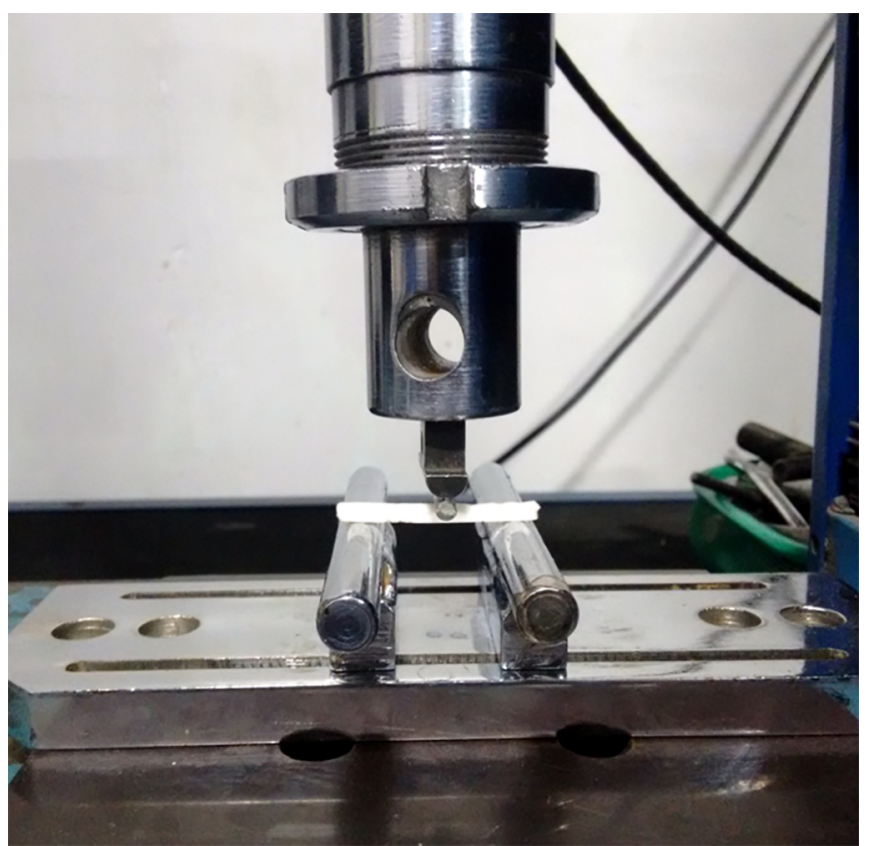

Fig. 5: Load applied on the samples for flexural strength

a function of deflection of the beam. The FS was calculated for all samples and subjected statistical analysis (Fig. 5).

\section{Micromechanical Characteristics}

Measurement of Vickers Hardness Test

After FS, the fragments of the three-point bending test were used to determine Vickers hardness ( $\mathrm{VH}$ ) by means of an automatic microhardness indenter. The test specimens were placed on the stage of the tester and stabilized. The measurements were carried out under controlled force. The test load applied is $50 \mathrm{~g}$ and the dwell time is 30 seconds. The penetration depth of the indenter (Diamond Indenter $136^{\circ}$ angle) was measured after the application of load at $600 \times$ magnification. The hardness was measured in HV (VH) (Figs 6 to 8).

\section{Results}

\section{Assessment of Flexural Strength}

Machine specifications: Universal testing machine (computerized, software-based) 

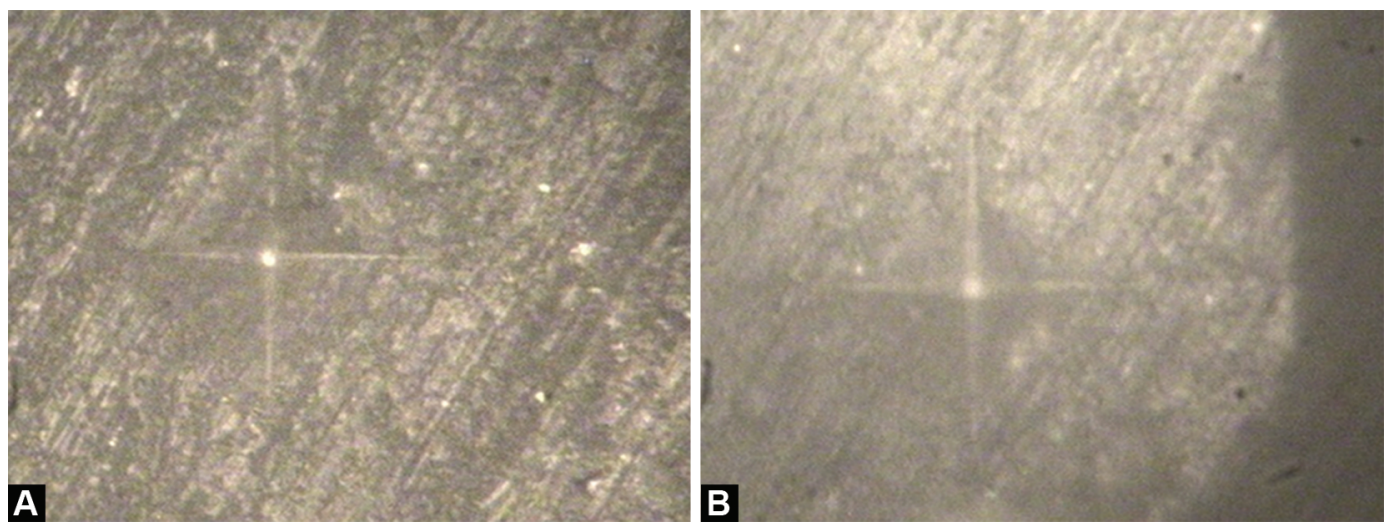

Figs 7A and B: Group I: Microscopic images after load applied for hardness test

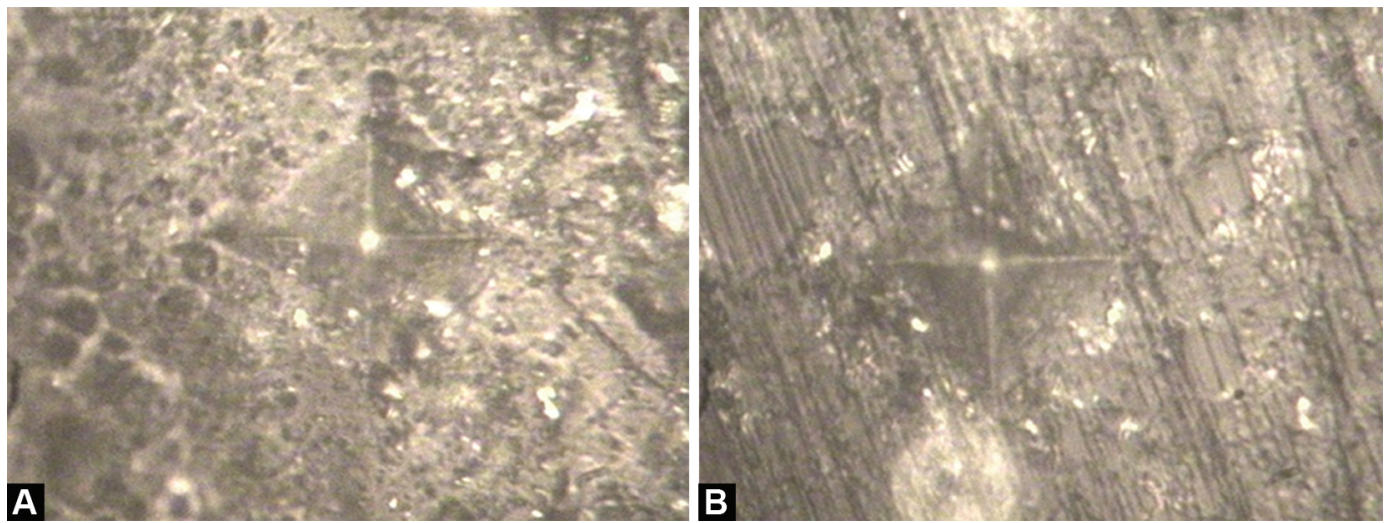

Figs 8A and B: Group II: Microscopic images after load applied for hardness test

Table 1: Flexural strength

\begin{tabular}{|c|c|c|c|}
\hline \multicolumn{4}{|c|}{ Flexural strength $(\mathrm{MPa})$} \\
\hline S. no. & Sample no. & $\begin{array}{l}\text { Group I: Zinc- } \\
\text { reinforced glass } \\
\text { ionomer cement } \\
(G I C)\end{array}$ & $\begin{array}{l}\text { Group II: GIC } \\
\text { type IX }\end{array}$ \\
\hline 1 & No. 1 & 12.92 & 23.56 \\
\hline 2 & No. 2 & 34.56 & 33.66 \\
\hline 3 & No. 3 & 20.56 & 31.38 \\
\hline 4 & No. 4 & 22.27 & 20.52 \\
\hline 5 & No. 5 & 15.57 & 18.18 \\
\hline 6 & No. 6 & 59.39 & 17.91 \\
\hline 7 & No. 7 & 34.52 & 28.77 \\
\hline 8 & No. 8 & 33.25 & 33.77 \\
\hline 9 & No. 9 & 30.52 & 19.11 \\
\hline 10 & No. 10 & 35.29 & 33.22 \\
\hline 11 & No. 11 & 21.87 & 14.95 \\
\hline 12 & No. 12 & 30.05 & 20.74 \\
\hline 13 & No. 13 & 18.04 & 28.25 \\
\hline 14 & No. 14 & 51.50 & 27.37 \\
\hline 15 & No. 15 & 42.33 & 42.61 \\
\hline 16 & No. 16 & 40.36 & 19.33 \\
\hline 17 & No. 17 & 41.63 & 20.39 \\
\hline 18 & No. 18 & 28.53 & 20.15 \\
\hline 19 & No. 19 & 40.07 & 25.68 \\
\hline 20 & No. 20 & 44.45 & 14.11 \\
\hline Average & & 32.884 & 24.683 \\
\hline
\end{tabular}

Table 2: Vickers hardness

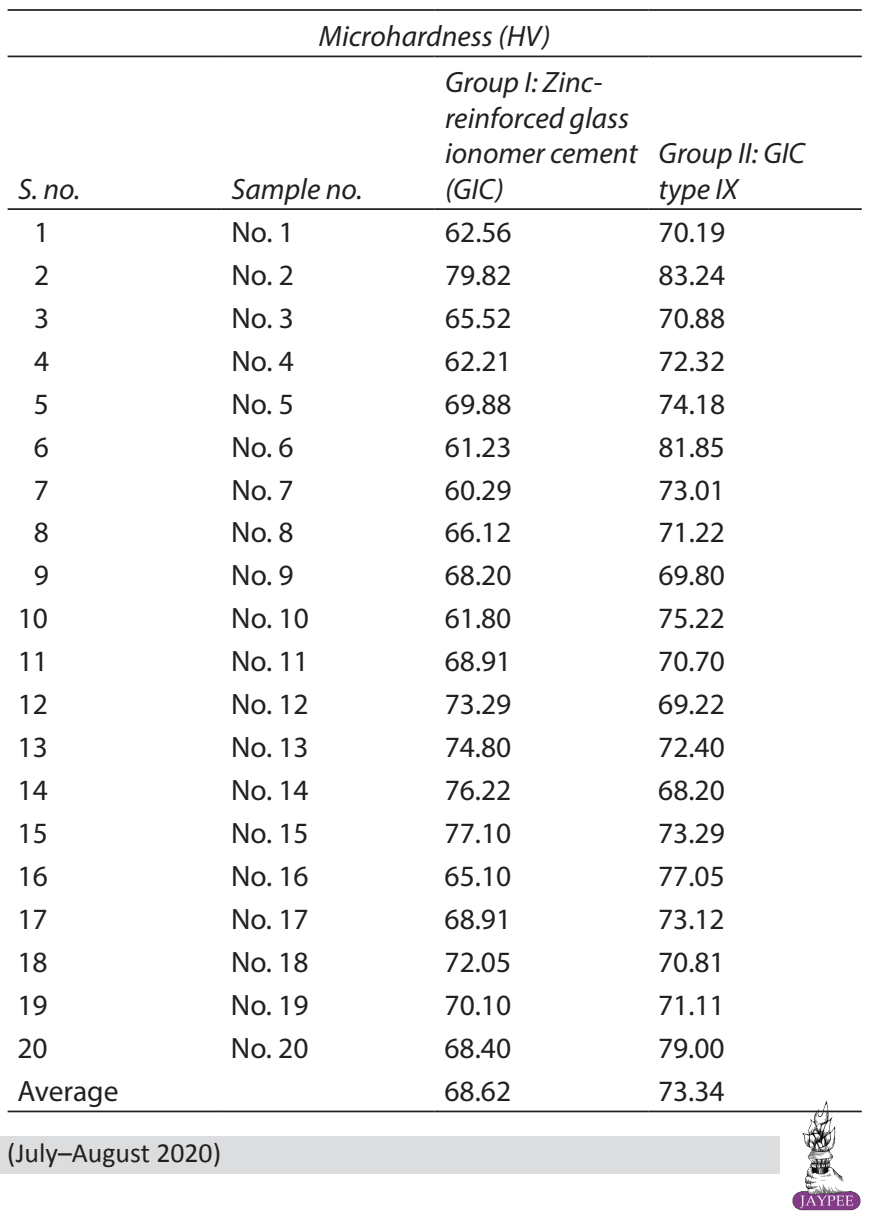




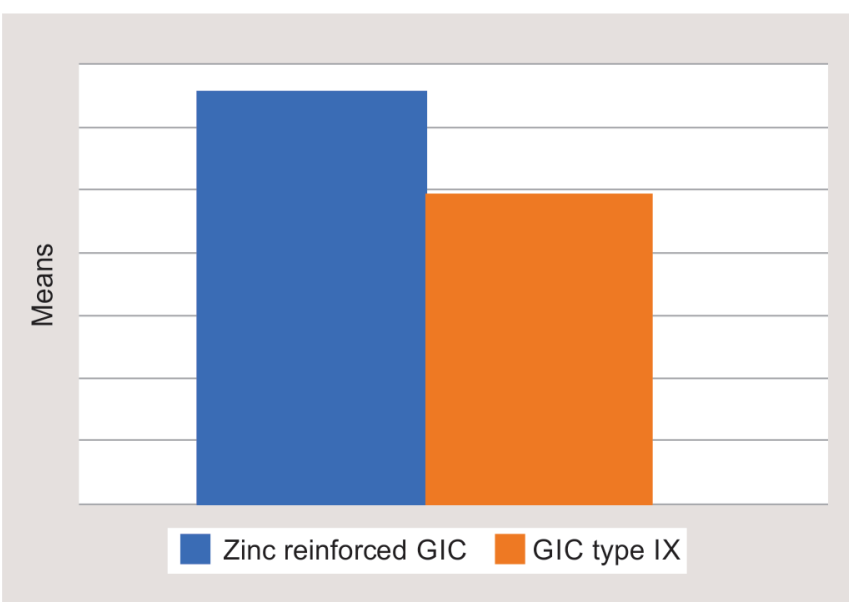

Fig. 9: Bar diagram for mean flexural strength

Table 3: Statistics for flexural strength (FS)

\begin{tabular}{lcl}
\hline & FS for group I & FS for group II \\
\hline Mean & 32.884 & 24.683 \\
Variance & 147.6134989 & 56.18003263 \\
Observations & 20 & 20 \\
$p$ value & 0.007530 & \\
\hline
\end{tabular}

Company: Star Testing System, India

Model No.: STS 248 ; accuracy of the machine: $\pm 1 \%$

C/h Speed: $3 \mathrm{~mm} /$ minute; distance between supports: $30 \mathrm{~mm}$ (Table 1)

\section{Assessment of Microhardness}

Machine specifications: Microhardness Tester, Reichert Austria Make, Sr. No. 3637

Load applied: $100 \mathrm{~g}$ (Table 2).

\section{Flexural Strength Method}

Group I: Zinc-reinforced GIC Group II: GIC type IX

Graphical representation of the data are given in Figure 9.

\section{Summary Statistics (Table 3) \\ Data Analysis}

- To test whether the average FS of zinc-reinforced GIC method and GIC type IX cement method is same or different significantly, we used two-sample $t$-test with unequal variances as the data are found to be from the same material. The normality is checked by using usual the normal probability plot.

Therefore, the null hypothesis $\left(\mathrm{H}_{0}\right)$ and the alternative hypothesis $\left(\mathrm{H}_{1}\right)$ are as follows:

- $\mathrm{H}_{0}$ : FS of zinc-reinforced GIC method and GIC type IX cement method is the same.

- $\mathrm{H}_{1}$ : FS of zinc-reinforced GIC method is superior (larger) to (than) GIC type IX cement method

- The $p$ value is found to be 0.007530 . Therefore, we reject the null hypothesis $\left(\mathrm{H}_{0}\right)$ at $0.75 \%$ level of significance.

- Hence, zinc-reinforced GIC method is superior to GIC type IX cement method with respect to FS.

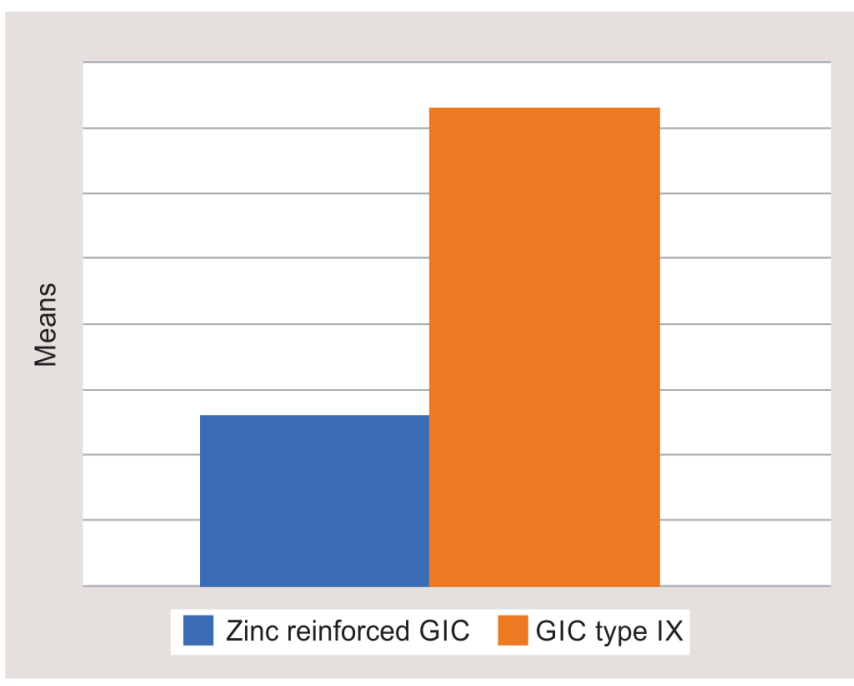

Fig. 10: Bar diagram for mean microhardness

\section{Microhardness in HV}

Group I: Zinc-reinforced GIC

Group II: GIC type IX

Graphical representation of the data are given in Figure 10.

\section{Summary Statistics (Table 4)}

Table 4: Statistics for Vickers hardness

\begin{tabular}{lll}
\hline & $\begin{array}{l}\text { Microhardness in HV } \\
\text { for group I }\end{array}$ & $\begin{array}{l}\text { Microhardness in HV } \\
\text { for group II }\end{array}$ \\
\hline Mean & 68.6255 & 73.3405 \\
Variance & 31.98013132 & 16.69953 \\
Observations & 20 & 20 \\
$p$ value & 0.0023 & \\
\hline
\end{tabular}

\section{Data Analysis}

- To test whether the average microhardness in HV of zincreinforced GIC method and GIC type IX cement method is same or significantly different, we used two-sample $t$-test with unequal variances as the data are found to be from the same material. The normality is checked by using the usual normal probability plot. Therefore, the null hypothesis $\left(\mathrm{H}_{0}\right)$ and the alternative hypothesis $\left(\mathrm{H}_{1}\right)$ are as follows:

- $\mathrm{H}_{0}$ : microhardness in HV of zinc-reinforced GIC method and GIC type IX cement method is the same.

- $\mathrm{H}_{1}$ : microhardness in HV of GIC type IX cement method is superior to zinc-reinforced GIC method.

- The $p$ value is found to be 0.0023 . Therefore, we reject the null hypothesis $\left(\mathrm{H}_{0}\right)$ at $0.23 \%$ level of significance.

- Hence, GIC type IX cement method is superior to zinc-reinforced GIC method with respect to microhardness in HV.

\section{Discussion}

Dental caries is the localized destruction of susceptible dental hard tissues by acidic by-products from bacterial fermentation of dietary carbohydrates. ${ }^{8}$ It is a dynamic process which alters the demineralization and remineralization of the tooth structure. The caries process is initiated in the bacterial biofilm over the tooth 
surface, and the signs of the carious destruction are seen on the hard dental tissues. However, though the caries process is started, the very early changes on the hard dental tissues cannot be detected with traditional clinical and radiographic diagnostic aids.

Caries is a multifactorial disease affected by the composition and flow of saliva, fluoride exposure, consumption of dietary fermentable sugars, and preventive measures. It starts with the microbiological shift within the complex biofilm. This dental caries can be intervened at any stage of progression and is initially reversible even though only some dentine or enamel is lost, provided with complete removal of biofilm. ${ }^{9}$

Dental caries is a chronic disease with slow progression in most of the population. Dental caries seen on the crown is called coronal caries and on the root is called as root caries of both primary and permanent teeth. It appears on the smooth surface as well as on pitted and fissured surfaces. It affects the outer covering of the crown called enamel and covering of the root called cementum along with the hard tissue beneath both enamel and cementum. Dental caries of preschool children in primary dentition is referred to as early childhood caries.

Dental caries can be considered as one of the most important pathological process in human being and bacteria plays a key role in their development. The treatment of dental caries will not completely eliminate all the microorganisms involved in the residual tissues. Streptococcus mutans are the major group of bacteria which are involved in initiating the carious lesion on the hard tooth surfaces of tooth. Reducing the number of $S$. mutans also reduces the caries activity. This shows the strong correlation between the number of $S$. mutans and the formation of new carious lesion as well as the metabolic activity of bacteria which is again closely related to the initiation and progression of the dental caries. ${ }^{9}$

Restorative dentistry completely removes caries applying the ultraconservative approach which helps to preserve the tooth structure and also prevents injury to the pulp. The treatment of dental caries which involves complete removal of caries needs the basic concept of deep carious dentin lesion to be understood, which is composed of two distinct layers. An outer layer which is infected dentin, highly contaminated and not recoverable. An inner layer of affected dentin, which is less frequently contaminated with bacteria and preserves the cross-banded ultrastructure of the collagen matrix and can be remineralized. With this concept of the presence of two layers in carious lesion, the objective of partial caries removal helps to eliminate only superficial carious highly infected dentin and to maintain the affected dentin which can be remineralized. ${ }^{10}$ The purpose ${ }^{11}$ of any restorative material is to

- Repair/limit the damage of dental caries

- Protect and preserve the remaining pulp and tooth structure

- Ensure adequate function and provide ease in maintaining good oral hygiene

Various clinical research have shown clinically that the variety of restorative materials completely removes caries with adequate sealing of the cavity ensuring that the dental caries lesions are arrested. ${ }^{12}$

However, some of the disadvantages were seen to achieve these goals; hence, restorative materials are manipulated with some additions in the basic composition to enhance their properties and to achieve these objectives.

So, the goal of the present study was to evaluate and compare the mechanical properties of two different restorative materials which were modified to improve the mechanical and physical properties, so that the objective of the restorative material can be achieved.

Glass-ionomer cement is considered to be the most important tool in the fighting against the development and prevention of dental caries. It acts as a reservoir of other ions including fluoride in the oral environment and a mechanical barrier between the surface of tooth and bacteria protecting the tooth surface. The most important property of GIC is that it can provide the most prominent seal under the most challenging clinical conditions in the oral cavity. Clinically, GICs are excellent restorative material of choice for the posterior teeth in primary dentition. The enamel of the primary teeth is less wear resistant than as compared with the enamel of permanent teeth and as primary teeth exfoliates and allows eruption of the permanent succedaneous teeth. Hence, the primary tooth restoration not needs to be as wear resistant as the restoration mandated for the permanent teeth. Therefore, GIC is a better choice as compared to amalgam and composite resins.

A critical property for GIC which makes them unique and different from other restorative materials is its ability to release fluoride from the glass particles to adjacent tooth surfaces. The prevention of bacterial growth is attributed to the fluoride-releasing ability of GIC. ${ }^{13}$

Setting reaction of GIC occurs in two phases. In the first phase, after mixing, immediate cross-linking of the poly-acid chains occurs by either the calcium or strontium ions present in the powder. This cross-linking during this first phase is unstable. In the second phase, within the set cement, the poly-acid chains undergo further crosslinking by trivalent aluminum ions. This phase of setting reaction gives the cement its improved physical properties and reduced solubility in the oral environment. ${ }^{14}$

Glass ionomer cement is a rich reservoir of ions such as fluoride, calcium, strontium, and phosphate which are apatite forming ions due to the combined effect of release and uptake of ions. Along with this, there is a natural exchange of strontium and calcium ions. To maintain electrolytic balance, when the strontium ions leave the set cement, an equivalent number of calcium ions from the saliva enters the matrix of the cement. ${ }^{14}$

In the set GIC, the are two types of water molecules loosely bound or tightly bound. As the set GIC matures, the material will show improved physical properties as the ratio between the loosely bound and tightly bound water molecules decreases. ${ }^{14}$

Although GIC is regularly used as a desirable restorative material in dentistry, they have disadvantages too.

- lack of sufficient strength

- lack of toughness

- technique-sensitive

- poor wear resistant

- resistance to fracture is poor

- unesthetic-few shades,

- low bond strength and compressive strength

In the last 15 years, to overcome major disadvantages of this glass ionomer cement, manufacturers have worked thoroughly to produce a desirable GIC material that can overcome the disadvantages.

It is important to assess the physical and mechanical properties of GIC as it mainly consists of ionomeric materials. Hence, this has to be considered by professionals to have a safe and desirable material for all the clinical situation. ${ }^{15}$ 
Scientist and researcher have introduced the products which have either avoided or reduced the major disadvantages of the material to the desirable levels.

Thus, to get better mechanical properties of traditional GIC, addition of chemicals was done in its composition. One of the recently done modification is the incorporation of zinc in the GIC.

Zinc-reinforced GIC has the properties desirable for restoration of the posterior teeth in primary dentition. The major modification in content is the addition of zinc in the glass powders along with a novel acrylic acid copolymer having increased molecular weight. Addition of both these materials helps to improve the setting reaction and also modifies the formed matrix. ${ }^{6}$

Amino acid-containing polymers have been reported to improve the mechanical properties of $\mathrm{GIC}\left(\mathrm{Kao}^{16}\right.$ et al., $\mathrm{Wu}^{17}$ et al., and Moshaverinia ${ }^{18}$ et al.) and RMGIC (Xie ${ }^{19}$ et al.). The amino acids, for example, glutamic acid, alanine, and aspartic acid, were first prepared as amino acid derivatives and were then used in polymerization with acrylic acid and itaconic or maleic acid monomers to obtain terpolymers. These amino acid derivatives allowed for attaching of carboxylic groups at certain distances away from the main backbone, resulting in greater ionic complex formation between carboxylic groups and $\mathrm{Al} 3+$ ions from the glass, thereby strengthening the set cement.

For a material to have long-term clinical performance, the restorative material should withstand the functional forces. Though various types of mechanical strength tests are available, the clinical validity and reproducibility to survive the glass ionomer materials of these in vitro tests is not yet identified. ${ }^{20}$

Prosser $^{21}$ et al. considered that FS is the most appropriate measurement to a glass ionomer material strength, as the material would fracture only at the anatomic level by either tensile or shear failure. Hence, the compressive strength is valuable to know the strength of a glass ionomer material. The compressive and tension stress acts on the material simultaneously, and the evaluation of these properties is important when the material is used for restoration of the posterior teeth. Considering the strength of material, there are various research available to evaluate the tensile and biaxial strength but no studies that evaluate the ultimate FS.

The composition of the selected materials greatly influences properties such as VH and FS. Various studies have also accepted that the chemical composition, concentration and molecular weight of the polycarboxylic acid, the glass structure, and the power/liquid ratio influence the strength of the material. ${ }^{22}$

Flexural strength is the ability of the material to bend before it undergoes breakage. ${ }^{23}$ It is evaluated when the ultimate flexibility of a material is achieved before its proportional limit. It is important for a dental material to withstand the needed repeated flexing, bending, and twisting due to the flexural forces generated usually in the clinical conditions. To prevent the permanent deformation of the restorative material, the material should have desirable high FS which constantly undergoes chewing stresses.

There are major laboratory tests which investigate products based on their bulk features. To evaluate material surface resistance to plastic deformation by penetration, the parameter used is surface hardness. It is not an intrinsic material property which defines considering the fundamental units of mass, length, and time. This surface hardness property value is the result of a defined measurement procedure. The commonly usual procedure to evaluate the hardness value is to measure the depth or area of an indentation left by an indenter of a specific shape with a specific force applied for a specific time. ${ }^{24}$

In the present study, it is observed that the mean value of FS of zinc-reinforced GIC is 32.88 (Fig. 9) and of GIC type IX is 24.683 (Fig. 9). So it states that FS of zinc-reinforced GIC is higher than glass ionomer type IX. This is in accordance with the study conducted by Molina ${ }^{25}$ stating that biaxial FS is higher of zinc-reinforced GIC than Fuji IX gold label. The highest FS observed with zincreinforced cement is $59.39 \mathrm{MPa}$ (Table 1) and that of GIC type IX is 42.61 (Table 1).

The mean VH observed in this study for zinc-reinforced GIC is $68.62 \mathrm{HV}$ (Fig. 10) and of GIC type IX is $73.74 \mathrm{Hv}$ (Fig. 10). So it states that VH of glass ionomer type IX cement is higher than zincreinforced glass ionomer cement. This is in accordance with study conducted by Al-Angari et al. ${ }^{26}$ stating that zinc-reinforced GIC had a greater increase in surface roughness with lower microhardness of the material. The highest $\mathrm{VH}$ observed with zinc-reinforced cement is $79.82 \mathrm{Hv}$ (Table 2) and that of GIC type IX is 83.24 (Table 2).

According to the manufacturer and also confirmed by results of this study, the evaluated restorative material has high molecular weight polyacids that improve the gelation caused by the formation of hydrogen bond and a novel glass-filler called reactive zincmodified fluoroaluminosilicate. The increased FS of the material was due to leached zinc ions form zinc-polyacid complexes; these complexes are stronger than the other bivalent strontium or calcium cations.

Prentice et al. ${ }^{27}$ gave another explanation of high FS of zincreinforced GIC and observed that improved strength of GIC is due to the increased glass surface area as there is a decrease in the mean particle size. Another study observed that the relative high fracture toughness of zinc-reinforced GIC could be due to complexes of zinc polycarboxylate formed during the setting reaction. ${ }^{6}$ Flexural and tensile strength of zinc-reinforced GIC might be increased due to the presence of itaconic acid as a comonomer. The relative high fracture toughness of zinc-reinforced GIC is its small mean particle size as compared with other conventional GICs has also been documented.

In the present study, it was observed that zinc-reinforced GIC had significant higher macromechanical properties (FS) and lowest micromechanical properties $(\mathrm{VH})$ in comparison with other GICs. The filler size and morphology of the glass particles ${ }^{28}$ in the zinc-reinforced GIC or the insufficient dispersion of zinc and glass particles could be the reason for lower micromechanical properties. There is evidence that the reason for weak mechanical properties is due to macrodefects in GICs, such as crazing and voids. Preheating the glass ionomer capsule is one of the technique that has been found to be effective in increasing the surface hardness of GIC. ${ }^{29}$

A zinc filler-modified high viscous glass-ionomer restorative material is more sensitive due to compositional heterogeneity which explains that this material is similar to metal-reinforced materials which are not harder or more durable. These zincreinforced GICs have increased due to accelerated ion release pattern over conventional GICs. ${ }^{30}$

The higher resistance of this new glass-ionomer when compared with that of the hand-mixed glass-ionomers is due to the presence of reactive glass fillers modified with zinc oxide that are easily released from the matrix and also the presence of increment of itaconic acid in the liquid of zinc-reinforced GIC which acts as network modifiers that increase the reactivity of the powder accelerating the maturation of the cement. ${ }^{6}$ The numerous extrinsic variability introduced in the use of hand-mixed glass-ionomers 
will affect the performance of the cement. These include powderto-liquid ratio, the number of porous elements or voids, and the precision of the clinician in inserting the mixture into the molds and into the prepared cavity. Hence, these variabilities are nullified by the use of encapsulated glass ionomers. ${ }^{31}$

The compressive strength, tensile strength, and the surface microhardness of the material are influenced by filler glass and powder/liquid ratio. Shintome et al. ${ }^{32}$ observed that higher powder/ liquid ratio showed higher microhardness. Xie et al..$^{33}$ reported that the worst mechanical property of materials was the result of less dense surface, or rather larger and higher amounts of voids.

The new zinc-reinforced GIC represents a promising approach of granting GIC with higher longevity, which can be used as more favorable filling material in class I, class III, and class V cavities, high stress bearing cases, cases requiring build-up, and in comprised clinical situations. In contrast to the GIC, the zinc-reinforced cement had improved macromechanical characteristics which showed better surface finish without visible surface irregularities, sets rapidly without the shrinkage of light cure, and no crack propagation.

The knowledge of the mechanical properties of various materials is important to support the exact indications of these materials and the expected long-term performance once placed in the oral cavity.

When evaluating the results of this study, it was noted that there may be limitations to the direct applications of in vitro study result to in-vivo situations. Due to the diversity among tested materials, the clinician should consider the actual clinical use of the most appropriate material with desirable properties.

Further clinical testing and in vivo investigations are still required to determine restorative material having the best mechanical properties. In spite of all modifications of GICs, there are still some technique sensitivity problems such as mechanical properties, physical properties, mixing consideration, setting reaction, and setting time. So, further research should aim at improving these properties.

\section{ConcLusion}

The new zinc-reinforced glass ionomer cement showed enhanced FS, thus increasing its longevity and turning into a more favorable filling material. In contrast to GIC, it showed better surface finish, sets quickly without the shrinkage of light cure or any crack propagation, and visible surface irregularities which improve the macromechanical properties of the material.

The knowledge of mechanical properties of various materials is important for the long-term clinical success of the material, and it is also important to select the appropriate material based on the clinical condition.

\section{References}

1. Nicholson JW. Chemistry of glass-ionomer cements: a review. Biomaterials 1998;19(6):485-494. DOI: 10.1016/s0142-9612(97) 00128-2.

2. de Souza Costaa CA, Ribeiro APD, Aparecida Giroc EM, et al. Pulp response after application of two resin modified glass ionomer cements in deep cavities of prepared human teeth. Dent Mater 2011;27(7):158-170. DOI: 10.1016/j.dental.2011.04.002.

3. Cehreli SB, Tirali RE, Yalcinkaya Z, et al. Microleakage of newly developed glass carbomer cement in primary teeth. Eur J Dent 2013;7(1):15-21.
4. Topbasi B, Lutfi oveçoglu M, Turkmen C. Flexural strength and fracture surface characterization of glass-ionomer cements stored in water. Oral Health Dent Manag 2003;2:18-26.

5. Glasspoole EA, Erickson RL, Davidson CL. Effect of surface treatments on the bond strength of glass ionomers to enamel. Dent Mater 2002;18(6):454-462. DOI: 10.1016/s0109-5641(01)00068-9.

6. Zoergiebel J, llie N. Evaluation of conventional glass ionomer cement with new zinc formulation: Effect of coating, aging and storage agents. Clin Oral Invest 2013;17(2):619-626. DOI: 10.1007/s00784-0120733-1.

7. Saleh LA, Khalil MF. The effect of different protective coatings on the surface hardness of glass ionomer cements. Saudi Dent J 1994;6(1).

8. Marsh P, Martin MV. Oral microbiology. 4th ed., Oxford: Wright; 1999.

9. Selwitz RH, Ismail Al, Pitts Al. Dental caries. Lancet 2007;369(9555): 51-59. DOI: 10.1016/s0140-6736(07)60031-2.

10. Ricketts $D$. Management of the deep carious lesion and the vital pulp dentine complex. Br Dent J 2001;191(11):606-610. DOI: 10.1038/ sj.bdj.4801246.

11. Guideline on Pediatric Restorative Dentistry AAPD 2008.

12. Orhan Al, Oz FT, Ozcelik B, et al. A clinical and microbiological comparative study of deep carious lesion treatment in deciduous and young permanent molars. Clin Oral Invest 2008;12(4):69-78. DOI: 10.1007/s00784-008-0208-6.

13. Wiegand A, Buchalla W, Attin T. Review on fluoride releasing restorative materials-fluoride release and uptake characteristics,antibacterial activity and influence on caries formation. Dent Mater 2001;23(3):343362. DOI: 10.1016/j.dental.2006.01.022.

14. Wilson AD, McLean JW. Glass-ionomer cement textbook 1998.

15. Market Shintome LK, Nagayassu MP, Di Nicolo R, et al. Microhardness of glass ionomer cements indicated for the ART technique according to surface protection treatnebt and storage time. Braz Oral Res 2009;23(4):439-445. DOI: 10.1590/S1806-83242009000400014.

16. Kao EC, Culbertson BM, Xie D. Preparation of glass ionomer cement using $\mathrm{N}$-acryloyl-substituted amino acid monomers-Evaluation of physical properties. Dent Mater 1996;12(1):44-51. DOI: 10.1016/ S0109-5641(96)80063-7.

17. Wu W, Xie D, Puckett A, et al. Synthesis of amino acid-containing polyacids and their application in self-cured glass-ionomer cement. Eur Polym J 2003;39(5):959-968. DOI: 10.1016/S0014-3057(02) 00308-7.

18. Moshaverinia A, Roohpour N, Darr JA, et al. Synthesis and characterization of a novel $\mathrm{N}$-vinylcaprolactam-containing acrylic acid terpolymer for applications in glass-ionomer dental cements. Acta Biomater 2009;5(6):2101-2108. DOI: 10.1016/j.actbio.2009. 02.015 .

19. Xie D, Chung I-D, Wu W, et al. Synthesis and evaluation of HEMAfree glass-ionomer cements for dental applications. Dent Mater 2004;20(5):470-478. DOI: 10.1016/j.dental.2003.07.003.

20. Turkun LS, Turkun M, Ertugrul F, et al. Long term antibacterial effects and physical properties of a chlorhexidine -containing glass ionomer cement. Jesthet Rest Dent 2008;20(1):29-45. DOI: 10.1111/j.17088240.2008.00146.x.

21. Prosser HJ, Powis DR, Wilson AD. Glass ionomer cements of improved flexural strength. J Dent Res 1986;65(2):146-148. DOI: $10.1177 / 00220345860650021101$.

22. Griffin SG, Hill RG. Influence of glass composition on the properties of glass polyalkenoate cements. Part I: Influence of aluminium to silicon ratio. Biomater 1999;20(17):1579-1586. DOI: 10.1016/s01429612(99)00058-7.

23. Ashby M. Butterworth-Heinemann materials selection in mechanical design 2011. p. 40

24. Craig RG. Mechanical properties. Restorative dental materials. 10th ed., St. Louis: Mosby; 1997. pp. 56-103.

25. Molina GF, Cabral RJ, Mazzola I, et al. Biaxial flexural strength of highviscosity glass-ionomer cements heat-cured with an LED lamp during setting. Bio Med Res Internat Vol 2013;2013:838460. 
26. Al-Angari SS, Hara AT, Chu T-M, et al. Physicomechanical properties of a zinc-reinforced glass ionomer restorative material. J Oral Sci 2014;56(1):11-16. DOI: 10.2334/josnusd.56.11.

27. Prentice LH, Tyas MJ, Burrow IU. The effect of particle size distribution on an experimental glass-ionomer cement. Dent Mater 2005;21(6):505-510. DOI: 10.1016/j.dental.2004.07.016.

28. Xie D, Brantley WA, Culbertson BM, et al. Mechanical properties and microstructures of glass-ionomer cements. Dent Mater 2000;16(2):129-138. DOI: 10.1016/s0109-5641(99) 00093-7.

29. Woolford MJ. Effect of radant heat on the surface hardness of galss polyalkenoate (ionomer) cement. J Dent 1994;22(6):360-363. DOI: 10.1016/0300-5712(94)90089-2.
30. Nakajima $\mathrm{H}$, Watkins $\mathrm{JH}$, Arita $\mathrm{K}$, et al. Mechanical properties of glass ionomers under static and dynamic loading. Art Dent Mater 1996;12(1):30-37. DOI: 10.1016/S0109-5641(96)80061-3.

31. Dowling Ah, Fleming GJ. Are encapsulated anterior glass ionomer restoratives better then their hand mixed equivalents,. J Dent 2009;37(2):133-140. DOI: 10.1016/j.jdent.2008.10.006.

32. Shintome LK, Nagayassu MP, Nicoló RD, et al. Microhardness of glass ionomer cements indicated for the ART technique according to surface protection treatment and storage time. Oral Res 2009;23(4):439-445. DOI: 10.1590/s1806-83242009000400014.

33. Xie D, Wu W, Puckett $A$, et al. Noval resin modified glass ionomer cements with improved Flexural strength and ease of handling. Eur Poly J 2004;40(2):343-351. 